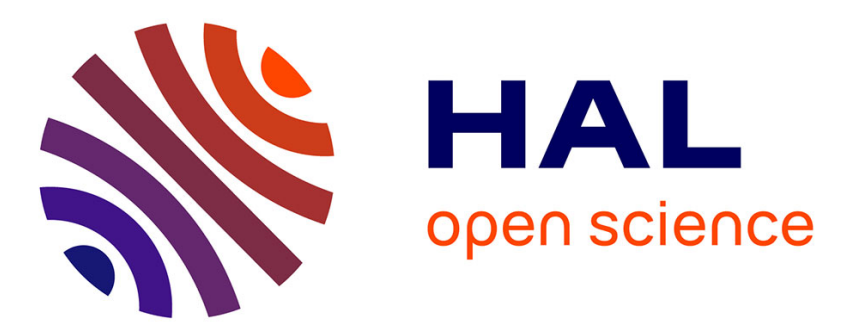

\title{
Identification of materials properties using displacement field measurement
}

\author{
Marina Fazzini, Olivier Dalverny, Sebastien Mistou
}

\section{To cite this version:}

Marina Fazzini, Olivier Dalverny, Sebastien Mistou. Identification of materials properties using displacement field measurement. Key Engineering Materials, 2011, vol. 482, pp. 57-65. 10.4028/www.scientific.net/KEM.482.57 . hal-00815850

\section{HAL Id: hal-00815850 https://hal.science/hal-00815850}

Submitted on 19 Apr 2013

HAL is a multi-disciplinary open access archive for the deposit and dissemination of scientific research documents, whether they are published or not. The documents may come from teaching and research institutions in France or abroad, or from public or private research centers.
L'archive ouverte pluridisciplinaire HAL, est destinée au dépôt et à la diffusion de documents scientifiques de niveau recherche, publiés ou non, émanant des établissements d'enseignement et de recherche français ou étrangers, des laboratoires publics ou privés. 


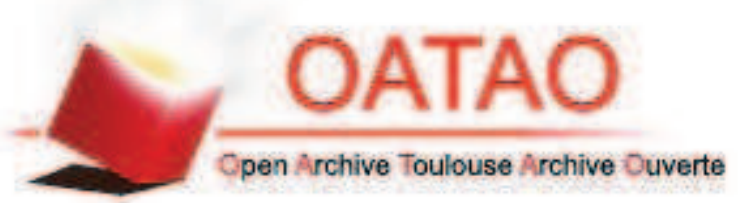

OATAO is an open access repository that collects the work of Toulouse researchers and makes it freely available over the web where possible.

This is an author-deposited version published in : http://oatao.univ-toulouse.fr/ Eprints ID : 8857

To link to this article : DOI:10. 4028/www.scientific.net/KEM.482.57

URL : http://dx.doi.org/10.4028/www.scientific.net/KEM.482.57

Open Archive TOULOUSE Archive Ouverte (OATAO)

To cite this version : Fazzini, Marina and Dalverny, Olivier and Mistou, Sebastien Identification of materials properties using displacement field measurement. (2011) Key Engineering Materials, vol. 482. pp. 57-65. ISSN 1662-9795

Any correspondence concerning this service should be sent to the repository administrator: staff-oatao@listes.diff.inp-toulouse.fr 


\title{
Identification of materials properties using displacement field measurement
}

\author{
M. Fazzini ${ }^{a}$, O. Dalverny ${ }^{b}$ and S. Mistou ${ }^{\mathrm{c}}$ \\ ENIT, University of Toulouse, LGP, 47 avenue d'Azereix 65000 Tarbes (France) \\ amarina.fazzini@enit.fr, ${ }^{b}$ olivier.dalverny@enit.fr , '@sebastien.mistou@enit.fr
} Key words: Parametric Identification, Inverse Methods, Stereo-correlation, Optical methods, Full-
Field Measurements

\begin{abstract}
The aim of this work is to identify parameters driving constitutive equations of materials with displacement field measurements carried out by image stereo-correlation during an unidirectional tensile test.

We evaluate two identification techniques. The first one is the virtual fields method which consists in writing the principle of virtual work with particular virtual fields. It is generally used in the case of linear elasticity and it requires a perfect knowledge of the model in terms of boundary condition since the virtual fields used must be kinematically admissible. This method allows to determine parameters by a direct and fast calculation, without iterations. The second method is the finite element model updating method. It consists in finding constitutive parameters that achieve the best match between finite element analysis quantities and their experimental counterparts. This method is more adaptable than the virtual field method but it needs to spend more calculation time.
\end{abstract}

\section{Introduction}

Advances in field measurements have enabled the development of identification techniques that are able to use part or all of the information obtained from the measurement. Two families of methods exist: iterative methods and non-iterative methods.

In order to identify materials properties from full field measurement, we chose to implement two methods. The first one, virtual fields method, is a non-iterative method which seems well suited to the identification of elastic properties from laboratory tests [1]. It is well documented and its implementation does not involve excessive developments. The second method is the finite element model updating method $[2,3]$. It is an iterative method which can be difficult to implement but it has many capabilities in terms of experience model and constitutive law.

The mechanical test chosen is a uniaxial tensile test performed on an aluminum 2024T4 sample, with $3 \mathrm{~mm}$ thickness. During this test, we performed displacement measurements by stereo-image correlation. This technique is a mix between Digital Image Correlation (DIC) and stereovision [4]. DIC is an optical full-field measurement technique which appeared twenty years ago [5]. It consists in recording with a camera some digital images of a specimen undergoing an in-plane displacement field and computing the image correlation by appropriate software. By adding a second camera and making a stereoscopic matching, out-of-plane measurements can be realized. The results obtained with the tensile test are shown in Figure 1. 


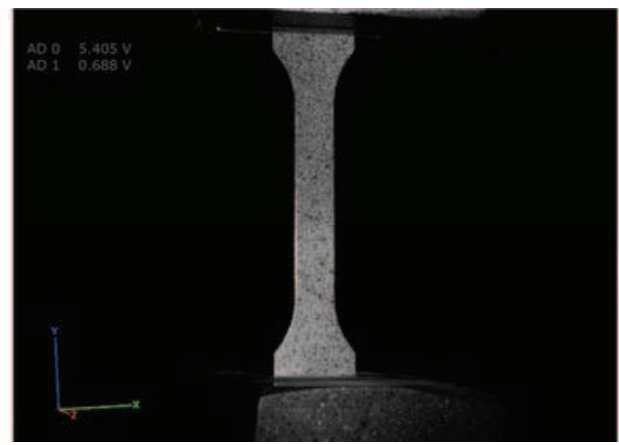

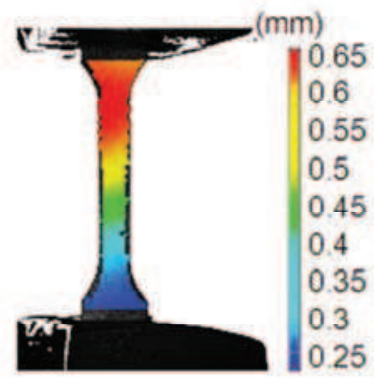

Ux

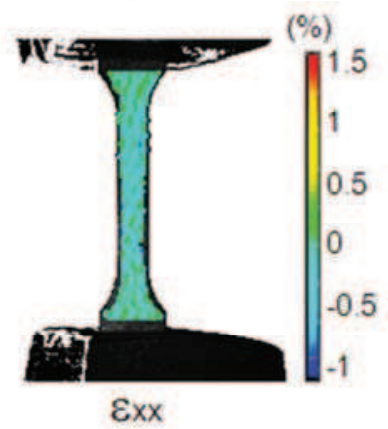

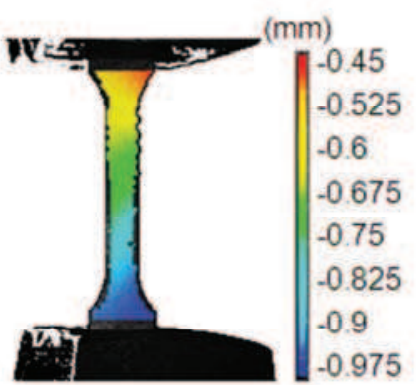

Uy

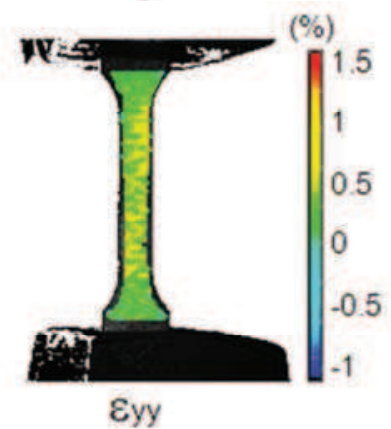

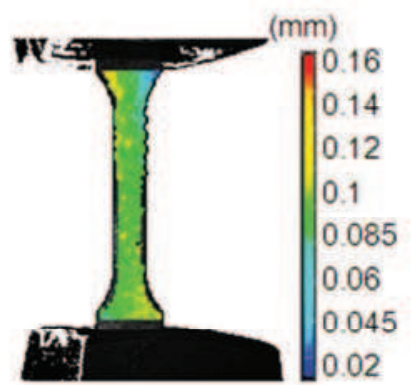

$\mathrm{Uz}$

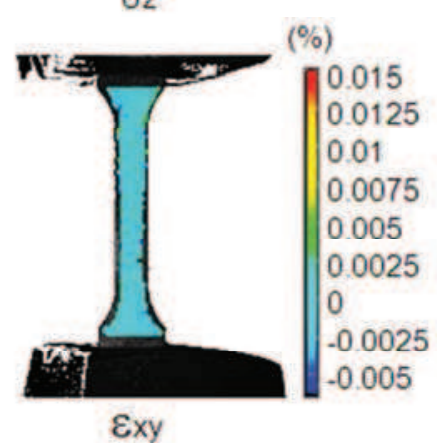

Fig. 1. Unidirectional tensile test on aluminum alloy $2024 \mathrm{~T} 4$

\section{Virtual Fields Method}

The first method used is the virtual fields method, which determines the material parameters (usually elastic), using the principle of virtual work with special virtual fields. To apply this method, we must make assumptions on the boundary conditions. For the model, we assume that the upper part of the specimen is fixed and a force of $11000 \mathrm{~N}$ is applied to the lower zone in the direction given by the axis of the specimen.

The principle of virtual work which reflects the static equilibrium of the specimen (with a volume $V$ ) undergoing a load modeled by the vector $\mathbf{T}$ at any point on the surface $S_{f}$ is written:

$$
\int_{V} \boldsymbol{\sigma}: \boldsymbol{\varepsilon}^{*} d V=\int_{S_{f}} \mathbf{T} \cdot \mathbf{u}^{*} d S
$$

where $\boldsymbol{\sigma}$ is the stress field and $\boldsymbol{\varepsilon}^{*}$ virtual strain field deduced from the virtual displacements $\mathbf{u}^{*}$ kinematically admissible. The choice of the virtual fields is an essential step. It is therefore necessary to select kinematically admissible fields which simplify the calculations. Thus, in our case, we can consider a first field defined by equations Eq. 2.

$$
\left\{\begin{array}{l}
u_{x}^{1 *}=0 \\
u_{y}^{1 *}=-y
\end{array}=>\left\{\begin{array}{l}
\varepsilon_{x}^{1 *}=0 \\
\varepsilon_{y}^{1 *}=-1 \\
\varepsilon_{s}^{1 *}=0
\end{array}\right.\right.
$$

where $x, y$ and $s$ are the contracted indices $(x=x x, y y=y, s=x y)$. 
With these virtual fields, and assuming that our material is homogeneous, isotropic and elastic, the first member of Eq. 1 becomes:

$$
\int_{V} \sigma_{i j}: \varepsilon_{i j}^{*} d V=-e S_{T}\left[C_{x x} \bar{\varepsilon}_{y}+C_{x y} \bar{\varepsilon}_{x}\right]
$$

with $\bar{\varepsilon}_{x}$ and $\bar{\varepsilon}_{y}$ averages of deformations along $x$ and $y, e$ is the thickness of the specimen and $S_{T}$ the measured surface.

For the simple tensile test, the virtual work of applied loading is written:

$$
\int_{S_{f}} T_{i} u_{i}^{*} d S=F L
$$

where $F$ is the applied force and $L$ is the length of the specimen.

Eq. 1 is written with the first virtual field (Eq. 2):

$$
C_{x x} \bar{\varepsilon}_{y}+C_{x y} \bar{\varepsilon}_{x}=-\frac{F L}{e S_{T}}
$$

Following the same approach, the use of a second virtual field (Eq. 6) can lead to a second equation (Eq. 7), thus forming with Eq. 5, a system of two equations with two unknowns, $C_{x x}$ and $C_{x y}$. This second virtual field is not strictly kinematically admissible but the contribution of efforts due to the fix to the virtual work of applied loading is considered null or negligible by the symmetry of these efforts to the vertical axis.

$$
\begin{gathered}
\left\{\begin{array}{l}
u_{x}^{2 *}=x \\
u_{y}^{2 *}=0
\end{array}=>\left\{\begin{array}{l}
\varepsilon_{x}^{2 *}=1 \\
\varepsilon_{y}^{2 *}=0 \\
\varepsilon_{s}^{2 *}=0
\end{array}\right.\right. \\
C_{x x} \bar{\varepsilon}_{x}+C_{x y} \bar{\varepsilon}_{y}=0 .
\end{gathered}
$$

The calculated parameters used to determine Young's modulus E and Poisson's ratio of our material by the following relations.

$$
\left\{\begin{array}{l}
E=C_{x x}\left(1-v^{2}\right)=-\frac{F L}{e S_{T} \bar{\varepsilon}_{y}} \\
v=\frac{C_{x y}}{C_{x x}}=\frac{-\bar{\varepsilon}_{x}}{\bar{\varepsilon}_{y}}
\end{array}\right.
$$

With the parameters of the specimen, we obtain an elastic modulus of $76447 \mathrm{MPa}$ and Poisson's ratio of 0.35 . It is possible to compare the results obtained by the virtual fields method with those obtained with standard experimental characterization. Young's modulus thus measured is set to $77232 \mathrm{MPa}$, Poisson's ratio come from the literature (Table 1). Both methods give close values.

Table 1. Results of the identification of elastic parameters of the aluminum $2024 \mathrm{~T} 4$ with virtual fields method

\begin{tabular}{ccc}
\hline & Experimental method & Virtual field method \\
\hline \hline Young modulus E $[\mathrm{MPa}]$ & 77232 & 76447 \\
Poisson ratio $v$ & 0.33 & 0.35 \\
\hline
\end{tabular}




\section{Finite element model updating method}

To implement the Finite element model updating method, we developed a specific application in Python language. The algorithm follows the flowchart in Fig.2. Its operation is described in the following paragraphs and is applied to the uniaxial tensile test, already described above.

Description of the application. The start point of the procedure consists of a mechanical test with the implementation of a stereo-image correlation system. Experimental data from these measurements, $u_{\text {exp }}$, are the displacements in the $\mathrm{x}, \mathrm{y}$ and $\mathrm{z}$ direction, measured for different load step.

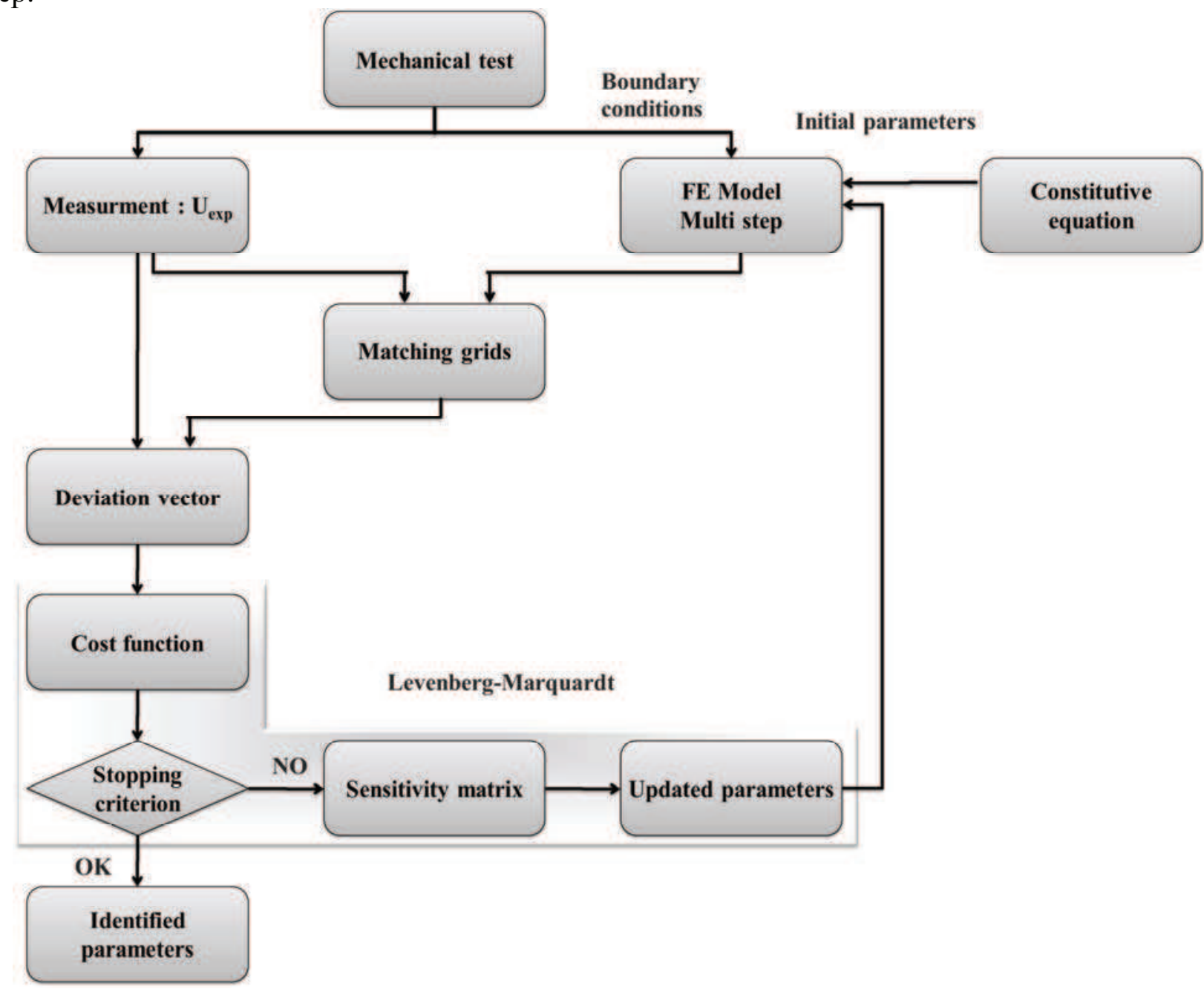

Fig. 2. Identification of the constitutive parameters, based on Levenberg-Marquardt algorithm

The model of the test is built using the Abaqus finite element code with a preselected behavior law that we want to identify. The boundary conditions used are derived from the test.

From a set of initial parameters (material parameters from the bibliography), a first calculation is performed, it allows to obtain the displacement field $u_{F E}$ of the specimen. The displacements are calculated at each node in the mesh of the finite element model. The mesh does not necessarily coincide with the experimental measurement grid used for stereo-image correlation, and therefore, to compare the two fields (experimental and numerical), it is necessary to know the values of the displacements at the same points. Thus, it is necessary to interpolate the results of finite element mesh around the points of the experimental grid. For this, the algorithm performs for each experimental grid point a research on the numerical grid of the three points that are closest neighbors. This research is conducted with the non-deformed grids. From the data collected, we calculate the displacements $\left(u_{n u m}\right)$ by linear interpolation, corresponding to the finite element model for the points of the experimental grid. 
The cost function described in Eq. 9 is built from the two displacement fields exp and num. The minimum of this cost function is evaluated by solving an iterative scheme like LevenbergMarquardt available in the Python library "scipy.optimize".

$$
J^{2}(\underline{p})=\sum_{k=1}^{l} \sum_{i=1}^{m} \sum_{j=1}^{n}\left(\left(u_{i j}^{\text {num }}(\underline{x})-u_{i j}^{e x p}\right)^{2}\right) .
$$

Application 1: identification of elastic parameters. The boundary conditions used for finite element model are derived directly from the test and can take into account the errors of positioning of the specimen in the grips and their misalignment. The upper grip (fixed side of the tensile machine) is controlled in displacement using data from the stereo-correlation. The lower grip (the crosshead side of the tensile machine) is controlled in displacement on the direction perpendicular to the axis of traction, while a force corresponding to that measured by the sensor of the machine is applied in the direction of the traction. To simplify the example, and after being assured they were negligible, out of plane displacement of the specimen were not taken into account.
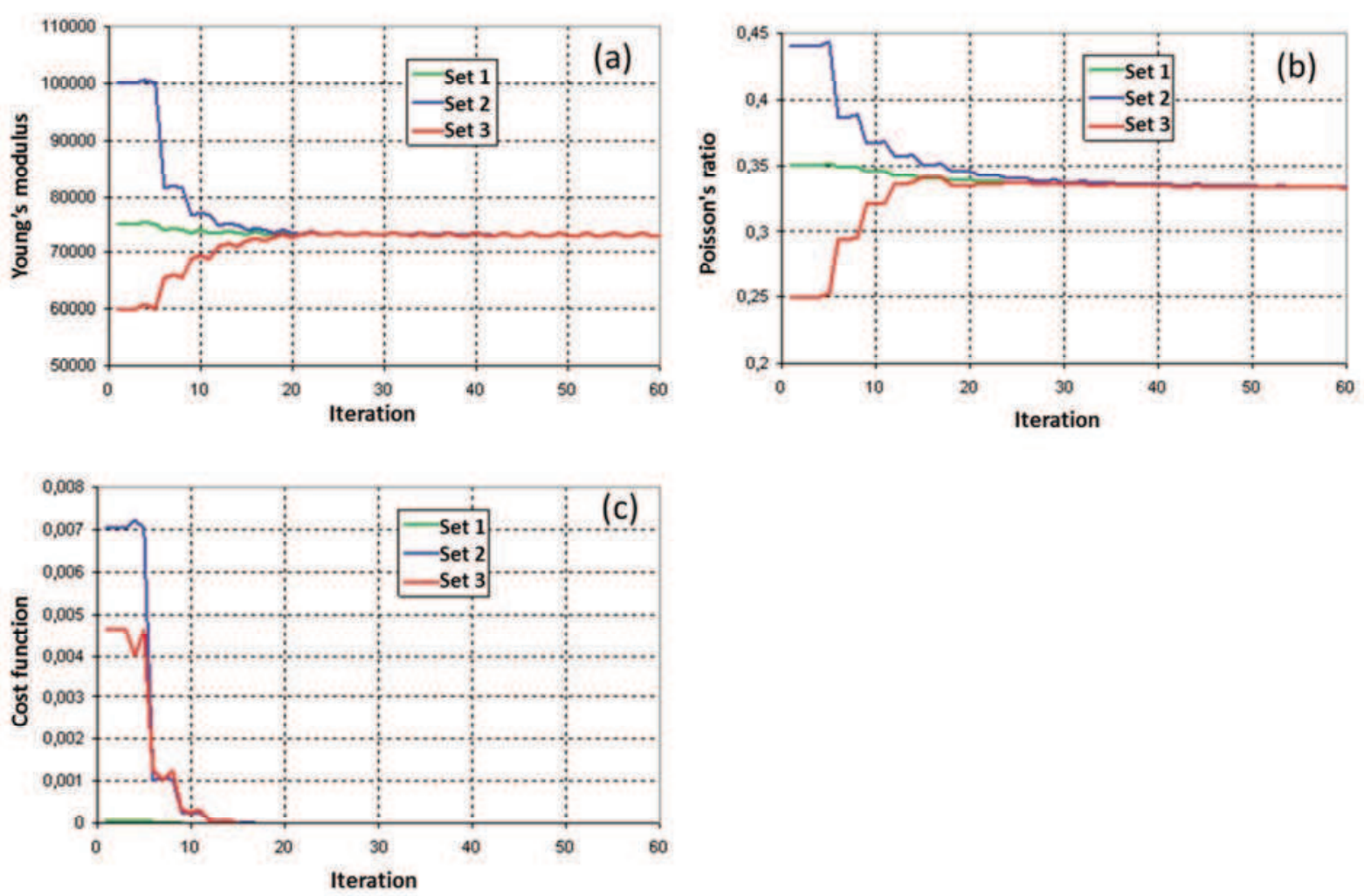

Fig. 3. Example of the evolution of the Young's modulus (a), the Poisson's ratio (b) and the cost function (c) for three different set of initial parameters

The application was evaluated with an experimental field to evaluate the Young's modulus E and Poisson's ratio $v$. The graphs in Fig. 3 provide for different sets of initial parameters, the evolutions of $\mathrm{E}, v$ and the cost function during the optimization process. We note that the algorithm converges to the same solutions for all points tested.

Figure 4 shows, for the same loading, the displacement field in $\mathrm{x}$ and $\mathrm{y}$ direction obtained experimentally and by finite element calculation. 
Table 2. Results of the identification of elastic parameters of the aluminum $2024 \mathrm{~T} 4$ with the finite element model updating method

\begin{tabular}{ccc}
\hline & Experimental method & Finite element model updating method \\
\hline \hline $\begin{array}{c}\text { Young modulus E } \\
{[\mathrm{MPa}]}\end{array}$ & 77232 & 73089 \\
Poisson ratio $v$ & 0.33 & 0.332 \\
\hline
\end{tabular}

The identification results are given in Table 2 . We observe that the modulus value obtained is less than the value measured with standard methods of characterization.
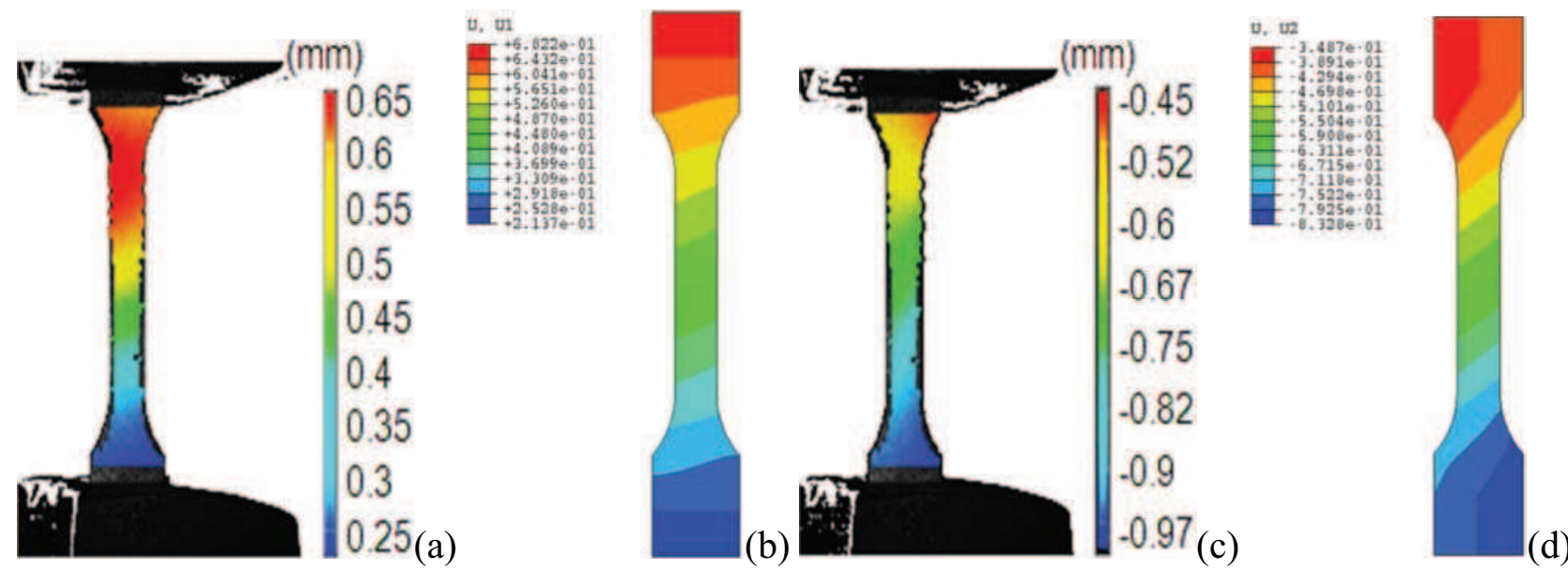

Fig. 4. Experimental displacement field on $\mathrm{x}$ and $\mathrm{y}$ direction ( $\mathrm{a}$ and $\mathrm{c}$ ) and FEM results $(\mathrm{b}$ and $\mathrm{d}$ )

Application 2: identification of elasto-plastic parameters. For the nonlinear behavior of the stress / strain curve we have chosen to use the Ramberg-Osgood model. This model was originally developed for aluminum alloys which can correctly take into account the different stages of the strain hardening curve, but it is also suitable for other metallic materials [6]. This model is integrated with the computer code Abaqus used to solve the direct problem. It is presented as follows:

$$
\varepsilon=\frac{\sigma}{E}+\frac{\alpha}{E}\left(\frac{|\sigma|}{\sigma_{0}}\right)^{n} \sigma
$$

where $\sigma$ is the stress, $\varepsilon$ the strain, $E$ the initial Young's modulus. $\alpha$ is a parameter called "Yield offset", that corresponds to the strain obtained when the stress reaches the yield strength, ie:

$\sigma=\sigma_{0} \rightarrow \varepsilon=\left((1+\alpha) \sigma_{0}\right) / E . n$ is an exponent reflecting the strain hardening of the material $(n>$ $1)$. 

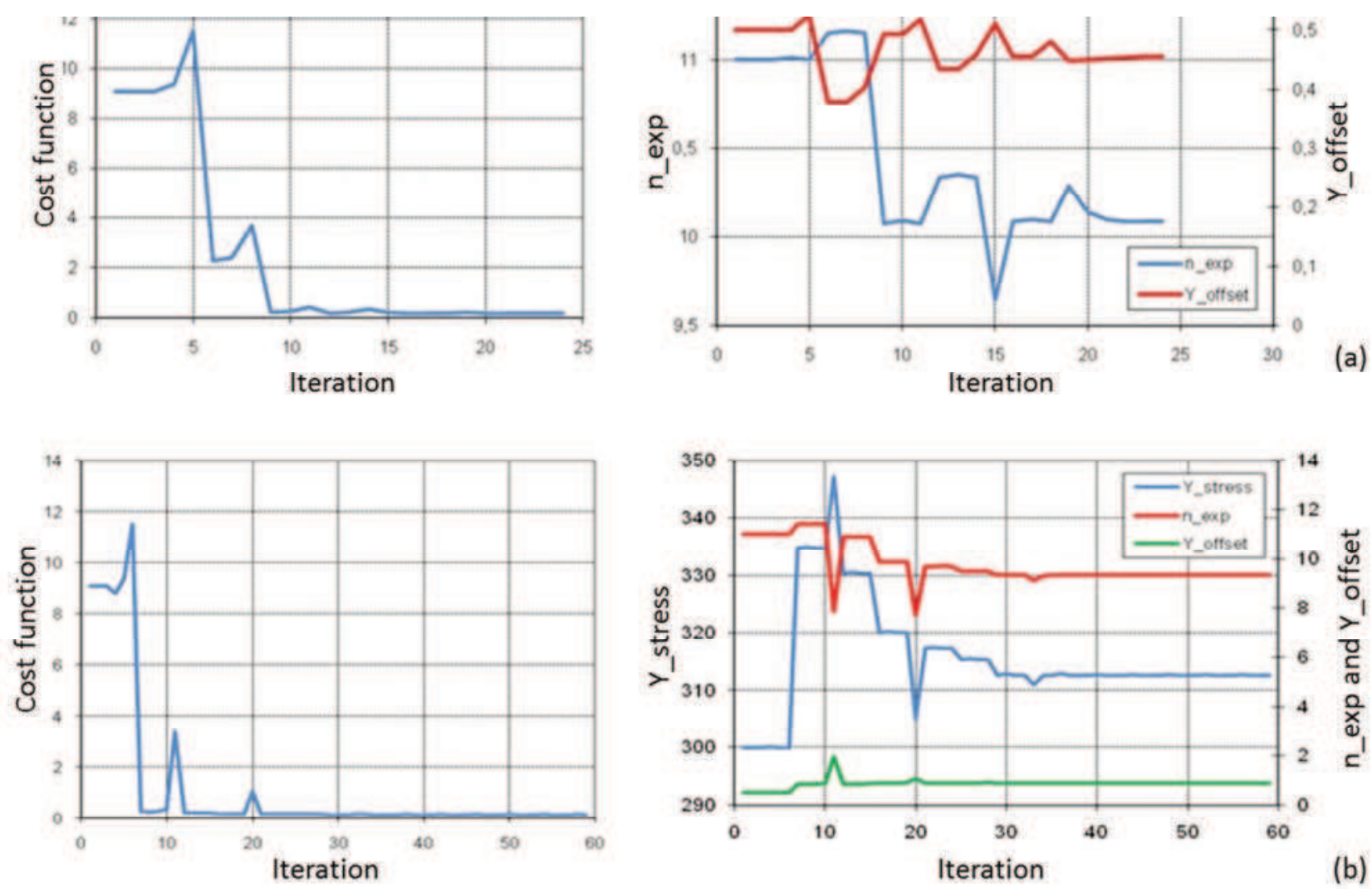

Fig. 5. Evolution of the cost function and of the identified parameters as a function of iteration for two variable parameters (a) and for three variable parameters (b).

Whatever the level of stress, this type of model is nonlinear, but the current values of the exponent $n$, order of 5 or more, the nonlinearity becomes significant only if the stress approaches or exceeds the yield strength $\sigma_{0}$.

We observe that from the moment we know the behavior of an elastic material, identify the Ramberg-Osgood model comes to identify the three parameters $\sigma_{0}, n$ and $\alpha$.

Table 3. Summary of results from the identification of parameters of the plasticity model of Ramberg-Osgood.

\begin{tabular}{ccccc}
\hline & $\sigma_{0}[\mathrm{MPa}]$ & $n$ & $\alpha$ & Deviation/exp. \\
\hline \hline Homogenous identification & 300 & 11.1223 & 0.2447 & 0.022 \\
FEMU - 2 parameters & 300 & 10.0842 & 0.4553 & 0.178 \\
FEMU - 3 parameters & 312.5 & 9.3286 & 0.8801 & 0.161 \\
\hline
\end{tabular}

To evaluate the ability of our application to identify a model of nonlinear behavior we used the same tensile test as previously. To get a reference for the comparison of the identified parameters, we initially conducted an identification through processing test as homogeneous. For this we use the tensile curve of our specimen instrumented with an extensometer. From the stress/strain curve, we have trained using the analytical model (Eq. 10), a cost function using the sum of squared deviations between the experimental curve and the analytical model. The minimization of the cost function by Newton's method yielded an initial set of parameters for the model (Table. 3). 


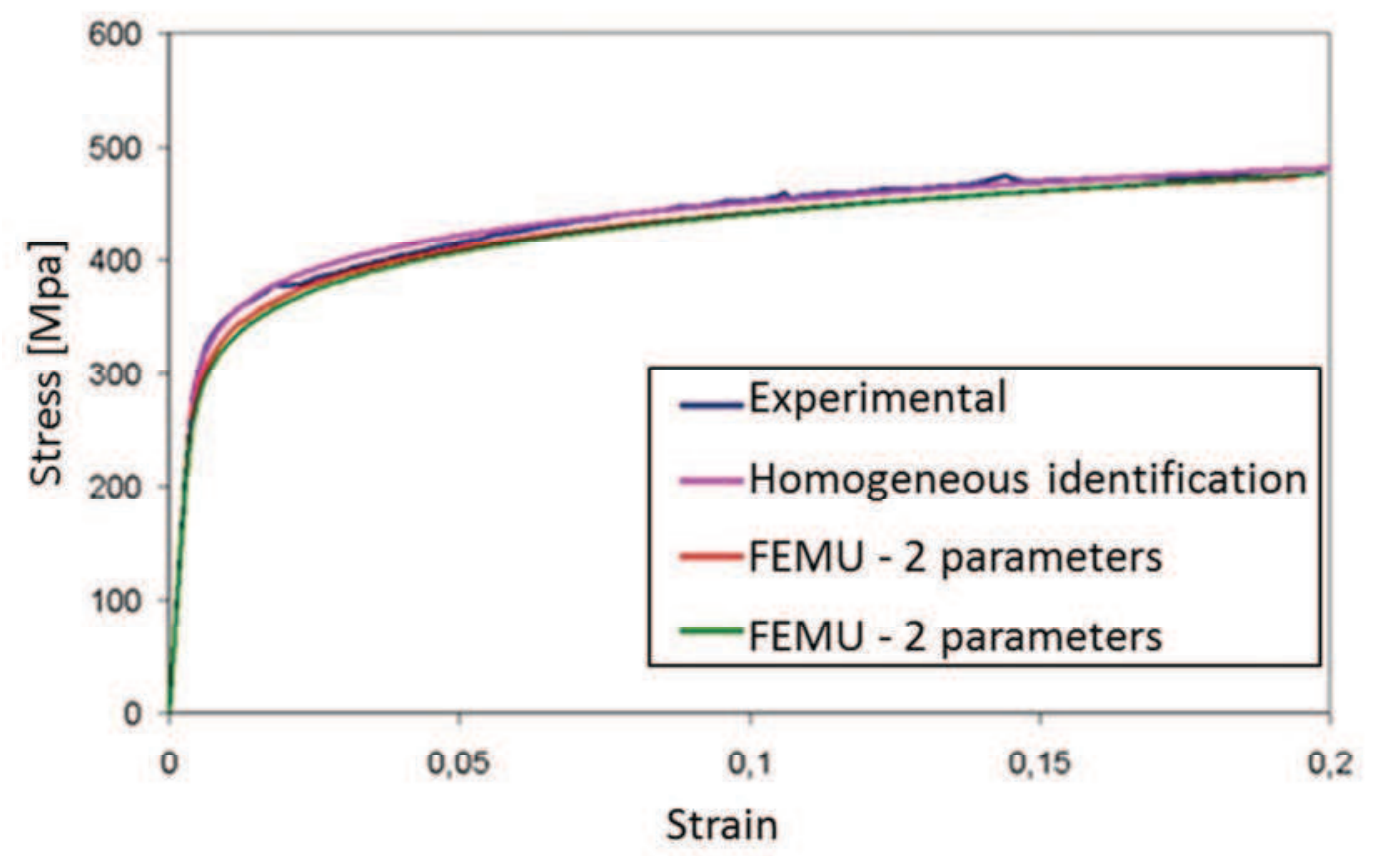

Fig. 6. Presentation of the different stress-strain curves constructed from the Ramberg-Osgood model whose parameters have been identified for aluminum 2024 T4

For the identification by finite element model updating, we considered that the elastic properties previously identified $(\mathrm{E}=73089 \mathrm{MPa}, v=0.332)$ were acquired. Two strategies have been implemented: the first considering an experimental yield strength measured at $300 \mathrm{MPa}$, the second leaving this parameter free. Thus, in the first case we have only two parameters to identify (because $\sigma_{0}=300 \mathrm{MPa}$ ) in the second case we have the three model parameters.

Fig. 5 shows for both cases treated the evolution of the cost function and parameters as a function of iterations. For the cases with 3 parameters to identify the number of iterations needed for convergence is almost three times higher than for the case with two parameters.

Table 3 includes all the results of the set of identified parameters. The first line refers to the classical parametric identification from a homogeneous specimen, while the other two are for identification by finite element updating with 2 and 3 parameters respectively for the second and the last line. We observe that all the identified parameters are fairly similar regardless of the method used. The last column shows, for the three identifications, measurement of the deviation between the models and experience. These small deviations reflect the good superposition of curve model results shown in Fig. 6.

\section{Conclusion}

Technical evolution of kinematic field measurements has encouraged the development of many types of identification by inverse methods. Among these, the virtual fields method and the finite element model updating method seem to be most suited to the identification of parameters controlling behavior laws. If the first is very efficient especially in terms of computing time since non-iterative, it remains difficult to apply to nonlinear problems.

The finite element model updating method remains, meanwhile, a robust technique and easily generalizable. It has been implemented successfully in this work to identify the elastic parameters and the plastic parameters of the behavior law of aluminum alloy $2024 \mathrm{~T} 4$. A limitation of the algorithm developed concerns the manipulation of large volumes of data from field measurements. Indeed, the multiplicity of measurement points and of loading steps slows significantly the progression of the calculation. Thus identifications were performed on small volumes of data. Additional work to optimize the code is still needed. 


\section{References}

[1] M. Grédiac. Principe des travaux virtuels et identification. Comptes rendus de l'académie des sciences. Série 2, $309: 1$ (1989).

[2] J.-P. Kleinermann. Identification paramétrique et optimisation des procédés de mise à forme par problèmes inverses. $\mathrm{PhD}$ thesis, Université de Liège (2000)

[3] N. Tardieu. Identification de lois de comportement élastoviscoplastique par indentation. $\mathrm{PhD}$ thesis, École polytechnique, France (2000).

[4] M. Sutton, W. Wolters, W. Peters, and S. McNiell, Determination of displacements using an improved digital correlation method, Image and Vision Computing Vol. 1 (1983), p. 133-139.

[5] J.-J. Orteu. 3-D computer vision in experimental mechanics. Optics and Lasers in Engineering, Optical Measurements Vol. 47 (2009), p. 282-291

[6] K.-J. Rasmussen. Full-range stress-strain curves for stainless steel alloys. Journal of Constructional Steel Research Vol. 59 (2003), p. 47-61 